\title{
DETECÇÃO DE CONTAMINANTES EM ESPÉCIE BIOINDICADORA (Corbicula fluminea) - RIO RIBEIRA DE IGUAPE - SP
}

\author{
Valéria Guimarães* e Joel Barbujiani Sígolo \\ Departamento de Geologia Sedimentar e Ambiental, Instituto de Geociências, Universidade de São Paulo, Rua do Lago, 562 ,
} 05508-080 São Paulo - SP, Brasil

Recebido em 17/10/07; aceito em 4/4/08; publicado na web em 4/9/08

\begin{abstract}
DECTECTION OF CONTAMINANTS IN A BIOINDICATOR SPECIES (Corbicula fluminea) - RIBEIRA DE IGUAPE RIVER, SAO PAULO STATE. The study assessed heavy metal concentrations in the tissue samples of Corbicula fluminea, by ICP-OES. In the tissues, average levels of $23.99 \mu \mathrm{g} / \mathrm{g}$ of $\mathrm{Cu}, 144.21 \mu \mathrm{g} / \mathrm{g}$ of $\mathrm{Zn}, 0.71 \mu \mathrm{g} / \mathrm{g}$ of $\mathrm{Cd}, 7.10 \mu \mathrm{g} / \mathrm{g}$ of $\mathrm{Cr}$ and $2.41 \mu \mathrm{g} / \mathrm{g}$ of Pb were detected ahowing that this last value is high and above the ANVISA reference $(2.00 \mu \mathrm{g} / \mathrm{g})$ for fish and other products. The results suggest that natural processes occuring in the Ribeira de Iguape River are not sufficient for purification so that metals remain in the water and can accumulate in the trophic chain.
\end{abstract}

Keywords: heavy metals; tissues of Corbicula fluminea; bioavailability.

\section{INTRODUÇÃO}

As análises de água e sedimentos são importantes para avaliação da contaminação ambiental por metais pesados em sistemas fluviais, mas não fornecem dados reais sobre a disponibilidade dos elementos aos organismos aquáticos. Desta forma, é necessário correlacionar os poluentes químicos, o ambiente em que estes poluentes se encontram e são liberados bem como a biota presente no ecossistema a ser analisado.

O emprego da biota em pesquisas de monitoramento ambiental data da década de 60 e foi utilizada na tentativa de quantificar a contaminação das águas da Califórnia por radionuclideos. Atualmente a biota tornou-se uma importante ferramenta em programas de monitoramento ambiental, uma vez que a biodisponibilidade é medida diretamente, sem suposições, como ocorre em outros métodos analíticos.

A biodisponibilidade de um elemento químico é a medida do potencial que o mesmo tem para ser absorvido pelos seres vivos, estando diretamente relacionada com a forma química deste composto no meio ambiente. ${ }^{1}$ A maior parte desses elementos pode ser transportada basicamente de dois modos: como espécies dissolvidas na água e/ou associadas às partículas sólidas.

As espécies que acumulam metais pesados ou outras substâncias em seus tecidos, e por esta razão podem ser usadas no monitoramento da biodisponibilidade destes compostos em um ambiente particular, recebem o nome de biomonitores ou bioindicadores. ${ }^{2}$ Os biomonitores e/ou bioindicadores fornecem medidas de tempo-integral dos níveis de biodisponibilidade de uma substância, aspecto que faz com que essas análises sejam superiores se comparadas com as realizadas em amostras de água e sedimentos, que podem variar extensamente devido à pequena mudança temporal.

Moluscos bivalves têm sido amplamente usados na avaliação de metais pesados em ambientes aquáticos, por fornecerem informações exatas e integradas sobre o impacto ambiental e biodisponibilidade de tais elementos. ${ }^{3-5}$

*e-mail:valguima@usp.br

\section{PARTE EXPERIMENTAL}

\section{Coleta e preparo das amostras}

A presente investigação foi desenvolvida na Bacia Hidrográfica do Rio Ribeira de Iguape, em decorrência do histórico de contaminação deste rio por atividades de mineração. Nesse rio foram coletados moluscos classificados como pertencentes ao filo Mollusca, classe Bivalvia, ordem Veneroida, família Corbiculidae e espécie Corbicula fluminea (Figura 1). A amostragem desses bivalves teve por finalidade a aplicação da técnica de espectrometria de emissão óptica na detecção de elementos potencialmente tóxicos (metais pesados), especificamente $\mathrm{Pb}, \mathrm{Cu}, \mathrm{Cr}, \mathrm{Zn}$ e $\mathrm{Cd}$, para avaliação da biodisponibilidade destes elementos nesse ambiente.

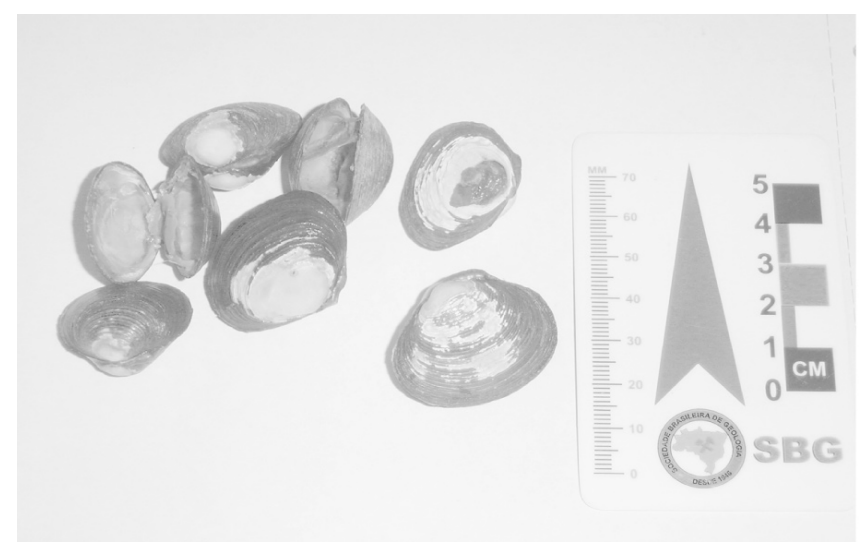

Figura 1. Bioindicador da espécie Corbicula fluminea

A coletada foi realizada manualmente através do exame tátil do sedimento de fundo no trecho fluvial que compreende o município de Iporanga até o de Registro, nos anos de 2004 e 2005 durante período climático de baixa pluviosidade. Os exemplares coletados foram acondicionados em sacos plásticos fechados a vácuo e foram congelados até o momento da análise.

Estes exemplares foram inicialmente descongelados à temperatu- 
ra ambiente e pesados. A parte mole (tecido) foi retirada com auxílio de uma espátula de teflon, lavada com água bi-destilada, seca parcialmente em papel de filtro e congelada até a data da análise, conforme metodologia empregada em Tomazelli. ${ }^{6}$ Além destes procedimentos, essas amostras foram todas liofilizadas e pesadas, sendo a seguir moídas em moinho criogênico para obtenção de amostras homogêneas, para posterior determinação dos metais pesados.

\section{Procedimento analítico}

Para determinação dos metais pesados nos tecidos dos bivalves, foi executado o seguinte procedimento: as amostras liofilizadas e moídas foram digeridas em frascos de teflon pressurizados em forno de microondas (Millestone). A seguir, $100 \mathrm{~g}$ do tecido recebeu $6 \mathrm{~mL}$ de ácido nítrico $20 \%$ e $2 \mathrm{~mL}$ de peróxido de hidrogênio, o resíduo foi dissolvido em ácido nítrico $0,1 \mathrm{~mol} / \mathrm{L}$ e completado até $10 \mathrm{~mL}$. Posteriormente, foi analisado em espectrômetro de emissão óptica com fonte de plasma modelo Optima 3000DV (Perkin Elmer). Nesta análise foi utilizado material de referência certificado pelo NIST SRM1566a (Oyster Tissue), obtendo-se resultados cuja concordância atingiu nível de $95 \%$ com os valores de referência. Esses procedimentos analíticos foram executados no Laboratório de Química Analítica do CENA "Henrique Bergamin Filho" Campus Piracicaba - USP.

\section{RESULTADOS E DISCUSSÃO}

As determinações de metais pesados nos tecidos de bivalves fornecem algumas informações a respeito dos níveis de contaminação do ambiente pesquisado, pois estes organismos são ótimos filtradores, acumulando as substâncias tóxicas presentes no ambiente aquático com eficiência em seus tecidos. Desta forma para avaliar a possível disponibilidade desses elementos adicionados no Rio Ribeira de Iguape a partir das atividades de mineração, analisaram-se os tecidos da espécie Corbicula fluminea coletada em quatro porções deste rio (CF-Ip Iporanga, CF-El Eldorado, CF-SB Sete Barras e CF-RE Registro).

Nestes tecidos (base seca) foram detectados metais pesados essenciais $(\mathrm{Cu}$ e $\mathrm{Zn})$ e não essenciais $(\mathrm{Cd}, \mathrm{Pb}$ e $\mathrm{Cr}$ ) para os processos biológicos desta espécie, como exibe a Tabela 1 .

Os valores médios de metais pesados detectados nestes tecidos foram da ordem de: 23,99 $\mu \mathrm{g} / \mathrm{g}$ de $\mathrm{Cu}, 144,21 \mu \mathrm{g} / \mathrm{g}$ de $\mathrm{Zn}, 0,71$ $\mu \mathrm{g} / \mathrm{g}$ de $\mathrm{Cd}, 2,41 \mu \mathrm{g} / \mathrm{g}$ de $\mathrm{Pb}$ e $7,10 \mu \mathrm{g} / \mathrm{g}$ de Cr. Neste rio, os tecidos dos exemplares coletados no segmento fluvial compreendido pelo município de Iporanga exibiram teores mais elevados de $\mathrm{Pb}(4,53$ $\mu \mathrm{g} / \mathrm{g})$ e de $\mathrm{Cr}(9,82 \mu \mathrm{g} / \mathrm{g})$, os coletados em Sete Barras apresentaram valores mais elevados para o $\mathrm{Zn}(180,90 \mu \mathrm{g} / \mathrm{g})$ e $\mathrm{Cd}(0,82 \mu \mathrm{g} / \mathrm{g})$ e os de Registro mostraram maiores teores de $\mathrm{Cu}(35,30 \mu \mathrm{g} / \mathrm{g})$, como observados na Tabela 1 e Figura 2.

Para todos os elementos aqui investigados, notam-se variações dos teores de uma localidade para outra, não é gradual o aumento ou decréscimo destas concentrações (Tabela 1). Isso ocorre, principalmente em decorrência do tamanho, idade e outros fatores fisiológicos dos

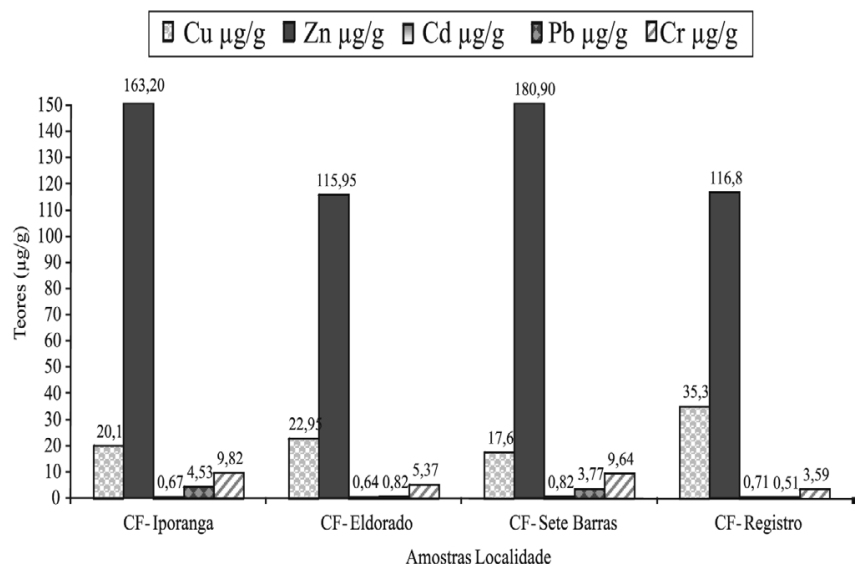

Figura 2. Distribuição dos teores de metais pesados nos tecidos (base seca) de Corbicula fluminea coletadas ao longo do Rio Ribeira de Iguape

bivalves analisados, como relatado na literatura especializada.,

As concentrações de $\mathrm{Pb}$ detectadas nos tecidos dos bivalves coletados em Iporanga $(4,53 \mu \mathrm{g} / \mathrm{g})$ e Sete Barras $(3,77 \mu \mathrm{g} / \mathrm{g})$ ultrapassam os limites máximos de tolerância para contaminantes inorgânicos em peixes e produtos de pesca estabelecidos pela legislação brasileira, valor de referência definido pela Portaria 658/98 da ANVISA, ${ }^{7}$ equivalente a $2,0 \mu \mathrm{g} / \mathrm{g}$ para este metal pesado. Esse padrão de referência foi empregado como indicativo de possível contaminação, tendo certa restrição quanto ao uso deste em face do mesmo ser empregado genericamente e não especificamente para os bivalves da espécie Corbicula fluminea, existindo variabilidade das condições fisiológicas dos organismos e dos parâmetros físico-químicos do ambiente.

Em todas as amostras o Cd está abaixo do padrão estabelecido pela Portaria 685/98 da ANVISA $^{7}$ que é da ordem de $1,0 \mu \mathrm{g} / \mathrm{g}$, como observado na Tabela 1.

Para verificar se os outros elementos detectados estavam em conformidade com teores obtidos para a Corbicula fluminea amostrada em ambientes fluviais não contaminados e contaminados, comparou-se os teores aqui obtidos com os determinados por outros pesquisadores, como visualizado na Tabela 2.

As amostras de Corbicula fluminea aqui investigadas exibiram baixas concentrações de Cd (média de $0,71 \mu \mathrm{g} / \mathrm{g}$ ), sendo estas inferiores às detectadas em áreas contaminadas por esse metal pesado, como visualizado na Tabela 2. 5, 6, 9,10 Essas concentrações são mais elevadas que as encontradas em bivalves de água doce para ambiente não contaminado, ${ }^{8}$ cujo teor detectado foi de $0,32 \mu \mathrm{g} / \mathrm{g}$ em espécie de Lampsilis ventricosa.

$\mathrm{O}$ teor de $\mathrm{Pb}$ detectado na amostra de Iporanga encontra-se acima dos valores relatados em outros trabalhos realizados com essa mesma espécie de bivalve (Tabela 2), como abordado anteriormente. Esse valor ultrapassa o limite de referência deste metal pesado estabelecido pela ANVISA ${ }^{7}$ definido para o consumo e comercialização de peixes e produtos de pesca. ${ }^{11}$ Em todas as amostras aqui analisadas os teores

Tabela 1. Teores de metais pesados detectados na base seca dos tecidos de Corbicula fluminea. ICP/OES - $\mu \mathrm{g} / \mathrm{g}$

\begin{tabular}{lccccc}
\hline Amostras & $\mathrm{Pb} \mu \mathrm{g} / \mathrm{g}$ & $\mathrm{Zn} \mu \mathrm{g} / \mathrm{g}$ & $\mathrm{Cr} \mu \mathrm{g} / \mathrm{g}$ & $\mathrm{Cu} \mu \mathrm{g} / \mathrm{g}$ & $\mathrm{Cd} \mu \mathrm{g} / \mathrm{g}$ \\
\hline CF-Ip & $4,53 \pm 0,06$ & $163,20 \pm 1,6$ & $9,82 \pm 0,11$ & $20,10 \pm 0,8$ & $0,67 \pm 0,02$ \\
CF-El & $0,82 \pm 0,03$ & $115,95 \pm 2,9$ & $5,37 \pm 0,11$ & $22,95 \pm 0,55$ & $0,64 \pm 0,01$ \\
CF-SB & $3,77 \pm 0,07$ & $180,90 \pm 1,7$ & $9,64 \pm 0,07$ & $17,60 \pm 0,3$ & $0,82 \pm 0,02$ \\
CF-Re & $0,51 \pm 0,08$ & $116,80 \pm 3,3$ & $3,59 \pm 0,12$ & $35,30 \pm 0,7$ & $0,71 \pm 0,02$ \\
Média & $2,41 \pm 0,06$ & $144,21 \pm 2,37$ & $7,10 \pm 0,10$ & $23,99 \pm 0,59$ & $0,71 \pm 0,02$ \\
Valor de Referência ANVISA & 2,00 & & & & 1,00 \\
\hline
\end{tabular}


Tabela 2. Comparação de teores de $\mathrm{Cu}, \mathrm{Cd}, \mathrm{Pb}, \mathrm{Cr}$ e $\mathrm{Zn}$ em tecidos de Corbicula fluminea de diversas localidades, coletados tanto em áreas contaminadas como em não contaminadas. Intervalo de Concentração e Média \pm Desvio Padrão ( $\mu \mathrm{g} / \mathrm{g}$ em peso seco)

\begin{tabular}{lccccccc}
\hline Locais de Coleta & $\mathrm{Cu} \mu \mathrm{g} / \mathrm{g}$ & $\mathrm{Cd} \mu \mathrm{g} / \mathrm{g}$ & $\mathrm{Pb} \mu \mathrm{g} / \mathrm{g}$ & $\mathrm{Cr} \mu \mathrm{g} / \mathrm{g}$ & $\mathrm{Zn} \mu \mathrm{g} / \mathrm{g}$ & Ref. & Tipo de Ambiente \\
\hline Rio Shatt al-Arab (Iraque) & $40-1065^{*}$ & $2,2-70^{*}$ & $0,3-3,2$ & nd & $31-83^{*}$ & 5 & Contaminado \\
Rio de La Plata (Argentina) & $45 \pm 18$ & $1,1 \pm 0,4$ & nd & $5,2 \pm 2,8$ & $197 \pm 54$ & 9 & Contaminado \\
New River (Va, USA) & $6,3-12$ & $5,9-6,9$ & nd & $8,2-55$ & $500-564$ & 10 & Contaminado \\
Rios do Estado de São Paulo & $0,39 \pm 0,33$ & nd & $3,67 \pm 3,87$ & nd & nd & 6 & \\
ANVISA $^{7}$ & & 1,0 & 2,0 & & & & \\
\hline
\end{tabular}

*Base Úmida; nd: Não determinado

de $\mathrm{Pb}$ foram maiores que os considerados para ambientes não contaminados, determinados em bivalves de água doce de várias espécies, como as que foram relatadas em espécie de Lampsilis ventricosa, ${ }^{8}$ cujo teor foi da ordem de $0,42 \mu \mathrm{g} / \mathrm{g}$.

\section{CONCLUSÕES}

Em vista dos resultados apresentados pôde-se concluir que o método analítico aplicado neste estudo (espectrômetro de emissão óptica - ICP/OES) mostrou-se apropriado para detecção de metais pesados em tecidos secos de bivalves de água doce; os exemplares de Corbicula fluminea coletados em diversos trechos do Rio Ribeira de Iguape podem ser empregados como bioindicadores da contaminação nesse ambiente fluvial, pois esses bivalves estão filtrando os elementos analisados, correlacionados à atividade de mineração na cabeceira e potencialmente tóxicos quando lançados no rio. Esses foram incorporados a esse rio a partir do lançamento de resíduos da mineração, encontrando-se hoje preferencialmente nos sedimentos, o que facilitou a assimilação de $\mathrm{Cu}, \mathrm{Zn}, \mathrm{Cd}$ e $\mathrm{Pb}$ por essa espécie bioindicadora.

Dos metais pesados provenientes dos resíduos de mineração, notou-se através desta pesquisa que o $\mathrm{Pb}$ exibe valores de concentração preocupantes, uma vez que esse é um metal não essencial e apresenta-se acima dos valores de referência detectados para outros bivalves em áreas contaminadas, além de estar acima do valor de referência da ANVISA.

Das localidades investigadas ao longo do Rio Ribeira, a porção próxima ao município de Iporanga foi a que exibiu maiores teores de $\mathrm{Pb}$ nos tecidos de Corbicula fluminea, isto ocorre em decorrência deste ponto estar mais próximo das antigas minas e de faixas de mineralizações ricas em $\mathrm{Pb}$ (Faixa Piririca).

De modo geral, verifica-se integração dos resíduos lançados no Rio Ribeira de Iguape e sua possível biodisponibilidade para biota, principalmente no caso do $\mathrm{Pb}$ e $\mathrm{Cd}$ contidos nestes resíduos e que este rio não está sofrendo processo natural de depuração, como muitas pesquisas afirmam.

\section{AGRADECIMENTOS}

À Fundação de Amparo a Pesquisa do Estado de São Paulo (FAPESP - Processo 02/09726-0) pela concessão da bolsa de estudo.

\section{REFERÊNCIAS}

1. http://www.planning.auckland.ac.nz, acessada em Março 2006.

2. Wagner, A.; Boman, J.; Acta Spect. Part B 2003, 59, 1125.

3. Phillips, D. J. H.; Environ. Pollut. 1997, 13, 282.

4. Tessier, A.; Campbell, P. G. C.; Can. J. Fish Aquat. Sci. 1984, 41, 1463

5. Abaychi, J. K.; Mustafá, Y. Z.; Environ. Pollut. 1988, 54, 109.

6. Tomazelli, A. C.; Tese de Doutorado, Universidade de São Paulo, Brasil, 2003.

7. http://e-legis.anvisa.gov.br, acessada em Fevereiro 2007.

8. Czarnezki, J. M.; Bull. Environ. Contam. Toxicol. 1987, 38, 641

9. Bilos, C.; Colombo, J. C.; Presa, M. J. R.; Environ. Pollut. 1998, 99, 1.

10. Rodgers, J. H. Jr., Cherry, D. S.; Graney, R. L.; Dikson, K. L.; Aquat. Toxicol. 1980, 266.

11. Guimarães, V.; Tese de Doutorado, Universidade de São Paulo, Brasil, 2007 